\title{
THE ASSOCIATION OF HAEMOGLOBIN AND FERRITIN CONCENTRATION IN NEWBORN AND CORD BLOOD WITH MATERNAL HAEMOGLOBIN AND FERRITIN CONCENTRATION IN THREE TRIMESTERS
}

\author{
Parul Singhal1, Meenu Rani², Sarandeep Singh Puri³ ${ }^{3}$ P. S. Dhot ${ }^{4}$, Ravi Sehgal ${ }^{5}$ \\ 1 Professor, Department of Pathology, SIMS, Hapur, Uttar Pradesh. \\ ${ }^{2} 3^{\text {rd }}$ Year Postgraduate Student, Department of Pathology, SIMS, Hapur, Uttar Pradesh. \\ ${ }^{3}$ Assistant Professor, Department of Pathology, SIMS, Hapur, Uttar Pradesh. \\ 4 Professor and HOD, Department of Pathology, SIMS, Hapur, Uttar Pradesh. \\ 5Professor, Department of Community Medicine, SIMS, Hapur, Uttar Pradesh.
}

\section{ABSTRACT}

\section{BACKGROUND}

Maternal nutrition and health is considered to be the most important regulator of human foetal growth. Improved maternal nutrition has been associated with increased foetal growth and a compromised maternal health leads to adverse birth outcomes in developing countries and in population with nutritional deficiencies.

Aims and Objectives- The present study evaluates the association of haemoglobin and ferritin concentration in newborn and cord blood with maternal haemoglobin and ferritin concentration in three trimesters.

\section{MATERIALS AND METHODS}

The study was observational, and design was longitudinal recruiting one hundred antenatal women in Saraswathi Institute of Medical Sciences and Hospital, Hapur. The haemoglobin and serum ferritin concentration of the mother in three trimesters was compared with the same in the cord blood and newborn. Maternal venous blood was taken during the first stage of labour. Sample of cord blood was collected soon after clamping and cutting the cord (Baby safely handed over to the paediatrician). The venous blood sample of the newborn was taken after 6 hours of delivery.

\section{RESULTS}

Maternal haemoglobin in the first and second trimester showed positive significant correlation with cord blood haemoglobin $(p<0.05)$. However, though the haemoglobin in third trimester showed positive correlation with cord blood, it was not significant. Correlation of haemoglobin in the first trimester was positive with the newborn haemoglobin ( $p=0.15)$. Haemoglobin in the second and third trimester showed positive correlations with newborn haemoglobin and that too significant. Haemoglobin status ranged from $9.0-12.3 \mathrm{mg} / \mathrm{dL}, 8.20-11.50 \mathrm{mg} / \mathrm{dL}$ and $7.5-10.8 \mathrm{mg} / \mathrm{dL}$ in the first, second and third trimester respectively. The mean haemoglobin concentration of study group during the first stage of labour was $8.7 \pm 1.0 \mathrm{mg} / \mathrm{dL}$. The mean haemoglobin concentration of cord blood was $14.1 \pm 1.2 \mathrm{mg} / \mathrm{dL}$, whereas it was $17.3 \pm 1.9 \mathrm{mg} / \mathrm{dL}$ in newborn. While the mean maternal ferritin was $17.37 \pm 2.02$ (normal $=12$ to $150 \mathrm{ng} / \mathrm{mL}$ ) and cord blood ferritin was $15.89 \pm 0.58$.

\section{CONCLUSION}

The findings suggest the requirement for establishing new strategies for ensuring that mothers take iron supplementation regularly and establishing nutritional education programs to improve the dietary intake of pregnant mothers. Also, regular investigations of pregnant mothers for $\mathrm{Hb}$ and other blood indices as well as ferritin should be performed. Awareness programs for medical staff concerning anaemia of pregnancy should be undertaken. Also, other research studies are needed to establish the normal values of anaemia indices in normal pregnant women and their babies.

\section{KEY WORDS}

Anaemia, Haemoglobin, Ferritin, Cord Blood.

HOW TO CITE THIS ARTICLE: Singhal P, Rani M, Puri SS, et al. The association of haemoglobin and ferritin concentration in newborn and cord blood with maternal haemoglobin and ferritin concentration in three trimesters. J. Evolution Med. Dent. Sci. 2018;7(19):2375-2379, DOI: 10.14260/jemds/2018/535

\section{BACKGROUND \\ Maternal nutrition and health is considered to be the most} important regulator of human foetal growth. Improved maternal nutrition has been associated with increased foetal growth and a compromised maternal health leads to adverse

'Financial or Other Competing Interest': None.

Submission 20-02-2018, Peer Review 18-04-2018,

Acceptance 24-04-2018, Published 07-05-2018.

Corresponding Author:

Dr. Sarandeep Singh Puri,

R-12/72, Raj Nagar,

Ghaziabad-201001, Uttar Pradesh.

E-mail: drsarandeep147@gmail.com

DOI: $10.14260 /$ jemds $/ 2018 / 535$ birth outcomes in developing countries and in population with nutritional deficiencies.

It is well known that nutritional intervention focused on woman's health during the reproductive stage, not only in the preconception period but also during the prenatal period helps achieve adequate newborn nutritional status and is reflected in childhood health and growth conditions. An important assessment of maternal nutrition has been since a long time the measurement of the haemoglobin levels to rule out anaemia due to iron, folate or vitamin B12 deficiency.

The World Health Organization (WHO) has estimated that about $40 \%$ of the world's population (More than 2 billion individuals) suffer from anaemia. In Asia, the prevalence of anaemia was estimated to be $44 \%$ in non-pregnant women and $60 \%$ in pregnant women. ${ }^{1}$ In developing countries, the 
prevalence of Iron Deficiency Anaemia (IDA) in pregnant women ranges from $35 \%$ to $75 \%$. Iron deficiency anaemia is the most frequent nutritional deficiency in pregnancy with an impact on maternal and foetal morbidity and mortality. It is regarded as the most important preventable cause of perinatal complications such as premature delivery, intrauterine growth retardation and neonatal and perinatal death. ${ }^{2}$

A number of studies have indicated that IDA during pregnancy may be associated with increased cases of prematurity and perinatal mortality. ${ }^{3}$ However, how IDA in pregnant women affects the iron metabolism and iron status of their foetuses remains to be established. The present study is undertaken to determine the association of maternal haemoglobin concentration in the three trimesters to the newborn haemoglobin concentration and cord blood haemoglobin.

\section{MATERIALS AND METHODS}

The study was observational, and the design was longitudinal (prospective) recruiting 100 pregnant women through consecutive sample selection among the antenatal population visiting the Department of Obstetrics and Gynaecology, Saraswati Institute of Medical Sciences (SIMS) and Hospital, Hapur (UP). The duration of the study was from July 2015 to Nov 2017. These antenatal women recruited in the study were followed up periodically till healthy delivery of their newborn babies in the Medical College.

\section{Inclusion Criteria}

Pregnant women (Aged 20 years or more) associated with SIMS Hospital during antenatal period and who followed-up up till healthy delivery were selected. Only singleton pregnancies, full-term neonates (37 - 41 weeks), primi or multiparous women and vaginal and caesarean section deliveries were included in the study.

\section{Exclusion Criteria}

Newborns with congenital malformation, mothers with antepartum haemorrhage, eclampsia and chronic gestational diseases such as diabetes mellitus, heart disease, kidney disease, lung disease, hypertension, birth asphyxia and HIV infection were excluded. Also, females with congenital malformations of uterus, those treated for pelvic inflammatory disease within 3 months prior to pregnancy or suffering with any bleeding disorder were not enrolled for the study.

Ethical approval was taken from the Institutional Ethical Committee after explaining the aims and objectives of the study. A written informed consent was obtained from each patient before initiating the study. The involvement of the subject was voluntary and deliberate.

\section{Statistical Analysis}

Statistical analysis was performed using SPSS (v 17.0). Differences between two parametric groups were compared by the Student ' $\mathrm{T}$ ' test and Pearson's correlational analysis. The level of significance was set at $5 \%(\mathrm{p}<0.05)$.

\section{RESULTS}

Majority of mothers were in the age group of 20 - 35 years. The mean age was $30 \pm 2.34$ years (mean \pm SD) and range was $20-45$ years. Socio-economic status of study participants according to Modified Kuppuswamy scale showed that $12 \%$ of them belonged to middle class, while $88 \%$ were from lower class (Figure 1).

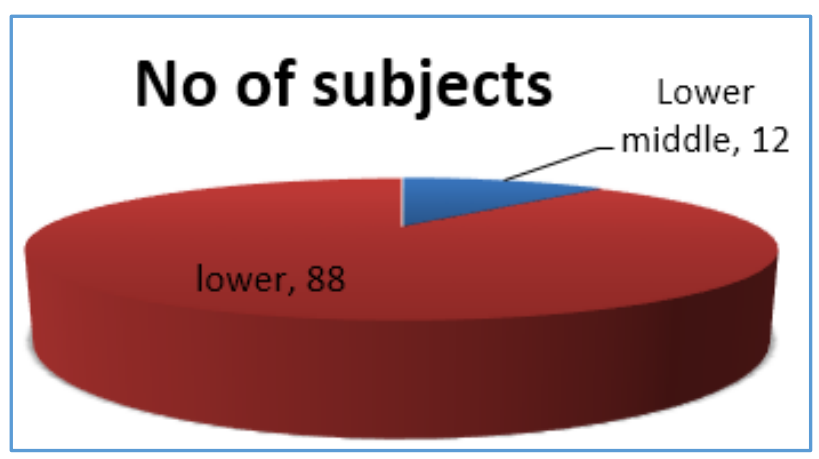

Figure 1. Socio-Economic Status of Study Participants

Nearly $41 \%$ of pregnant women were nulliparous, while $40 \%$ of women already had one child. Approximately, $14 \%$ of study participants had 2 children, 3 women had 3 and 2 women had 4 children respectively.

Trimester wise, haemoglobin concentration is depicted in Table 1. While the mean haemoglobin in the first trimester (Hb1) was $10.49 \pm 1.01 \mathrm{mg} / \mathrm{dL}$, it declined to $9.69 \pm 1.32$ $\mathrm{mg} / \mathrm{dL}$ in second trimester $(\mathrm{Hb} 2)$ and rose to $8.99 \pm 0.83$ $\mathrm{mg} / \mathrm{dL}$ in third trimester ( $\mathrm{Hb} 3$ ). Haemoglobin status ranged from $9.0-12.3 \mathrm{mg} / \mathrm{dL}, 8.20-11.50 \mathrm{mg} / \mathrm{dL}$ and $7.5-10.8$ $\mathrm{mg} / \mathrm{dL}$ in first, second and third trimester respectively. First and third quartiles of $\mathrm{Hb}$ concentration in all the three trimesters are also depicted.

\begin{tabular}{|c|c|c|c|c|}
\hline & \multicolumn{3}{|c|}{ Haemoglobin Concentration (gm/dL) } \\
\hline & & $\begin{array}{c}\text { First } \\
\text { Trimester } \\
\text { (Hb1) }\end{array}$ & $\begin{array}{c}\text { Second } \\
\text { Trimester } \\
\text { (Hb2) }\end{array}$ & $\begin{array}{c}\text { Third } \\
\text { Trimester } \\
\text { (Hb3) }\end{array}$ \\
\hline \multicolumn{2}{|l|}{ Mean } & 10.488 & 9.6880 & 8.988 \\
\hline \multicolumn{2}{|c|}{ Std. Deviation } & 1.01 & 1.32 & 0.83 \\
\hline \multicolumn{2}{|c|}{ Minimum } & 9.0 & 8.20 & 7.5 \\
\hline \multicolumn{2}{|c|}{ Maximum } & 12.3 & 11.50 & 10.8 \\
\hline \multirow{3}{*}{ Percentiles } & 25 & 9.500 & 8.7000 & 8.000 \\
\hline & 50 & 10.400 & 9.6000 & 8.900 \\
\hline & 75 & 11.400 & 10.6000 & 9.900 \\
\hline
\end{tabular}

The range of $\mathrm{Hb}$ level in first trimester ranged from 9.0 to 12.3, whereas it declined from 8.2 to 11.5 in the second trimester. In the third trimester, it further decreased from 7.5 to 10.8 among study subjects.

Table 2 shows other maternal and cord blood parameters. While the mean maternal ferritin was $17.37 \pm 2.02$, cord blood ferritin was $15.89 \pm 0.58$. The mean maternal folate was $3.47 \pm 0.40$ and mean maternal B12 was $78.19 \pm 9.11$. The mean birth weight was $2.732 \pm 0.33 \mathrm{~kg}$.

\begin{tabular}{|c|c|c|c|}
\hline & Mean & Std. Deviation & N \\
\hline Maternal Ferritin & 17.37 & 2.02 & 100 \\
\hline Cord Blood Ferritin & 15.89 & 0.58 & 100 \\
\hline Table 2. Mean Distribution of other Maternal and Cord \\
Blood Ferritin \\
\hline
\end{tabular}




\section{Association of Maternal Haemoglobin with Cord Blood} and Newborn Blood

Maternal haemoglobin in the first and second trimester showed positive significant correlation with cord blood haemoglobin $(\mathrm{p}<0.05)$. However, though the haemoglobin in third trimester showed positive correlation with cord blood, it was not significant (Table 3).

\begin{tabular}{|c|c|c|}
\hline \multirow{2}{*}{$\mathrm{Hb} 1$} & Pearson Correlation & Hb Cord Blood \\
\cline { 2 - 3 } & Sig. (2-tailed) & 1.000 \\
\hline \multirow{2}{*}{$\mathrm{Hb} 2$} & Pearson Correlation & $0.03^{*}$ \\
\cline { 2 - 3 } & Sig. (2-tailed) & 0.922 \\
\hline \multirow{2}{*}{$\mathrm{Hb} 3$} & Pearson Correlation & $0.001^{*}$ \\
\cline { 2 - 3 } & Sig. (2-tailed) & 0.227 \\
\hline \multicolumn{2}{|c|}{$\begin{array}{c}\text { Table 3. Correlation of Maternal Haemoglobin in Three } \\
\text { Trimesters with Cord Blood Haemoglobin }\end{array}$} \\
\hline
\end{tabular}

$* \mathrm{p}<0.05$

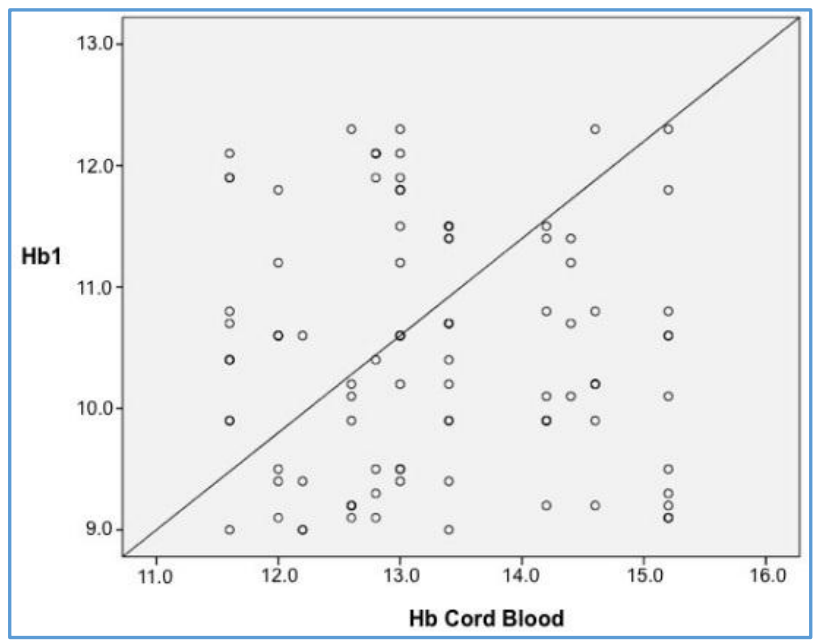

Figure 2. Scatter Diagram showing the Correlation of Hb1 with Hb of Cord Blood

Figure 2 shows the scatter diagrams of Haemoglobin concentrations of sample population in first ( $\mathrm{Hb} 1)$, second ( $\mathrm{Hb} 2)$ and third ( $\mathrm{Hb} 3$ ) trimesters in relation to Cord Blood $\mathrm{Hb}$. This figure shows the scatter diagrams to be of linear type.

As shown in Table 4, correlation of haemoglobin in first trimester was positive with newborn haemoglobin, but it was not significant $(\mathrm{p}=0.15)$. Haemoglobin in second and third trimester showed positive correlations with newborn haemoglobin and that too significant $(\mathrm{p}<0.05)$.

\begin{tabular}{|c|c|c|}
\hline & & Hb Newborn \\
\hline \multirow{2}{*}{ Hb1 } & Pearson Correlation & 0.471 \\
\hline & Sig. (2-tailed) & 0.15 \\
\hline \multirow{2}{*}{$\mathrm{Hb} 2$} & Pearson Correlation & 0.894 \\
\hline & Sig. (2-tailed) & $0.031^{*}$ \\
\hline \multirow{2}{*}{$\mathrm{Hb} 3$} & Pearson Correlation & 0.974 \\
\hline & Sig. (2-tailed) & $0.012^{*}$ \\
\hline \multicolumn{3}{|c|}{$\begin{array}{l}\text { Table 4. Correlation of Maternal Haemoglobin in Three } \\
\text { Trimesters with Newborn Haemoglobin }\end{array}$} \\
\hline
\end{tabular}

$* \mathrm{p}<0.05$

It is therefore seen that while haemoglobin in the first stage of labour showed strong positive correlation with haemoglobin of cord blood $(r=0.984 ; p=0.021)$, it showed no correlation with cord blood ferritin levels. Similarly, maternal ferritin levels showed significant positive correlations with haemoglobin of cord blood ( $\mathrm{p}<0.05)$.

\section{DISCUSSION}

The present study was a randomised, longitudinal study involving one hundred pregnant subjects (more than or equal to 20 years of age) over a span of 2 years (July 2015 to Nov 2017) reporting at Department of Pathology, previously referred from Department of Obstetrics and Gynaecology at Saraswathi Institute of Medical Sciences and Associated Hospitals, Hapur, Uttar Pradesh (India).

The study participants after scrutinizing through inclusion and exclusion criteria were evaluated. Ethical approval and informed consent were obtained. An expected association between maternal haemoglobin status at every trimester and haemoglobin and ferritin status of newborns was observed as per the evidence.

Iron Deficiency Anaemia (IDA) is the most common type of anaemia among pregnant women, especially in developing countries. ${ }^{1}$ The risk of IDA is particularly high in women with high parity and short intervals between pregnancies. Iron transfer from mother to foetus occurs against the concentration gradient. Maternal iron is the only source of foetal iron. It is logical, therefore that maternal iron status will affect the iron status of the neonate.

\section{Characteristics of the Study Population}

All pregnant women included in this study were between 25 \pm 45 years old (mean $=30.01 \pm 2.34$ ). The period interval of the women included in this study are ranging between $25 \pm$ 45 years old, because most of the Indian women are married at early ages nearing or above 20 years old, thereby at the age of 25 years they have babies which may consume more iron from the maternal stores during each gestation.

Haemoglobin levels during pregnancy are considered proxy indicators of the nutritional status of foetus as well, as maternal anaemia can have deleterious effects on it. It is associated with preterm birth, low birth weights and a small for gestational age foetus. ${ }^{4}$ However, several studies have also reported that iron deficiency in mothers during pregnancy does not influence the foetal iron supply. With this ambiguity, the present study was undertaken to study the association of maternal haemoglobin in three trimesters with cord blood and newborn haemoglobin level.

The mean haemoglobin levels declined from first to third trimester in our study from 10.49 to $8.99 \mathrm{mg} / \mathrm{dL}$. This trend is in line with those reported in other studies elsewhere. This may have been caused both due to increased demand of nutrients as well as by haemodilution associated with water retention during pregnancy.

The mean cord blood haemoglobin in the current study was $14.1 \mathrm{mg} / \mathrm{dL}$, which is lower than reported in the studies from west. This finding may be due to the fact that the nutritional status of females in the west is better than that in this part of the world, which is reflected in better iron stores and higher cord haemoglobin. Overall average haemoglobin of healthy term neonates is $16.8 \mathrm{mg} / \mathrm{dL}$, which is in consonance with the finding in our study.

Measurement of serum ferritin concentrations has been shown to be a good index of iron store.5,6 In our study, the maternal and cord blood serum ferritin levels were lower 
than reported elsewhere. However, with $10 \mu \mathrm{g} / \mathrm{L}$ as our cutoff for serum ferritin concentration to define iron deficiency, majority of the pregnant women had normal iron stores.

That majority of the newborn babies showing low iron stores despite the fact that majority of the women studied had normal iron stores may corroborate with a report by Agarwal et al,7 who concluded that mothers with reasonably maintained ferritin and transferrin saturation levels provide sufficient iron for maintenance of cord haemoglobin, although foetal iron stores are likely depleted.

Maternal haemoglobin in the first and second trimester showed significant positive correlation with cord blood haemoglobin in the present study. Previous studies have shown that there is a direct relationship between maternal and foetal haemoglobin demonstrating that the cord haemoglobin is lower in anaemic mothers and that the decrease appears to be proportional to the degree of anaemia. $^{8}$

Also, the foetus takes iron in direct proportion to the levels available in the mother. Trimester wise association presents some interesting facts. Similar to our results, a study from China has reported association of cord blood haemoglobin with anaemia in all the trimesters, but with a reverse trend. The authors had observed a strong association of first trimester anaemia and the least association of third trimester anaemia. ${ }^{9,10}$

Few other studies have also reported a similar trend. Currently, this still remains as a dogma. Though this association is convincing, this study could not provide any information about the possible mechanism. Maternal $\mathrm{Hb}$ versus uterine dynamics or other foetoplacental complex relations are subjects of further intensive research, which could explain such an association.

Similarly, maternal haemoglobin in the second and third trimesters showed significant positive correlation with newborn haemoglobin levels. Evidence suggests that third trimester $\mathrm{Hb}$ is an important factor in determining haematological parameters in newborn. Iron and other micronutrient accretion rates are the highest in the same trimester as well.

Interestingly, our study did not find any association between maternal and cord blood ferritin levels. Serum ferritin is a good measure of iron storage in the body, particularly of the reticuloendothelial system. Some investigators have also reported similar observations. According to them, the foetus continues to extract iron efficiently from the mother regardless of her iron status.

It is well known that iron is actively transported from mother to foetus. In the iron deficiency state, there is upregulation of iron transport proteins in the placenta, thus ensuring an adequate iron supply to the growing foetus even in the anaemic mother. ${ }^{11,12}$ This also suggests that placental iron transport mechanisms may not work at higher degrees of anaemia, thus leading to a fall in cord haemoglobin.

\section{Limitations of the Study}

A research group of 100 individuals may not be diagnostically sufficient for concluding such evidences. A larger sample size with preferably a cohort-based evaluation would be more helpful. Other parameters, particularly useful in determining anaemic status and iron stores like serum folate and vitamin B12 would also have been helpful in judging the status of the nutrition status. ${ }^{13}$ Most of the clinical parameters are a superficial estimate of the condition; however, a repeated analysis of the parameters with daily/ weekly recording should be noted.

\section{CONCLUSION}

The present study concludes that there is a significant association between maternal haemoglobin statuses with newborn haemoglobin levels in neonates. Serum ferritin is a more sensitive indicator of iron stores than haemoglobin and provides a good indication of iron status.

Maternal haemoglobin in the first and second trimester showed significant positive correlation with cord blood haemoglobin, while in third trimester it was not significant.

On the other hand, maternal haemoglobin in the first trimester was not significantly associated with newborn haemoglobin, while significant positive correlation is seen in second and third trimesters indicating that the maternal anaemia should be well looked after in the later months of pregnancy until the delivery. Maternal ferritin showed significant association with haemoglobin of cord blood.

\section{REFERENCES}

[1] Debbarma R, Debbarma B, Devi MA. Effect of maternal anaemia on cord haemoglobin and birth weight of newborns. IOSR Journal of Dental and Medical Sciences (IOSR-JDMS) 2015;14(7): Ver. IV, p. 19-21.

[2] De Sá SA, Willner E, Pereira DTA, et al. Anemia in pregnancy: impact on weight and in the development of anemia in newborn. Nutr Hosp 2015;32(5):2071-9.

[3] Woodman AG, Care AS, Mansour Y, et al. Modest and severe maternal iron deficiency in pregnancy are associated with fetal anaemia and organ-specific hypoxia in rats. Sci Rep 2017;7:46573.

[4] Tunkyi K, Moodley J. Anemia and pregnancy outcomes: a longitudinal study. J Matern Fetal Neonatal Med 2017;11:1-5.

[5] Najeeba CM, Prabhu AS, Saldanha PRM. Maternal anemia and its effect on cord blood hemoglobin and newborn birth weight. IOSR Journal of Dental and Medical Sciences 2015;14(7):30-2.

[6] Kumar KJ, Asha N, Murthy DS, et al. Maternal anemia in various trimesters and its effect on newborn weight and maturity: an observational study. International Journal of Preventive Medicine 2013;4(2):193-9.

[7] Agrawal RM, Tripathi AM, Agarwal KN. Cord blood haemoglobin, iron and ferritin status in maternal anaemia. Acta Paediatr Scand 1983;72(4):545-8.

[8] Dreyfuss ML, Stoltzfus RJ, Shrestha JB, et al. Hookworms, malaria and vitamin A deficiency contribute to anemia and iron deficiency among pregnant women in the plains of Nepal. J Nutr 2000;130(10):2527-36.

[9] McArdle HJ, Andersen HS, Jones H, et al. Copper and Iron transport across the placenta: regulation and interactions. Journal of Neuroendocrinology 2008;20(4):427-31.

[10] United Nations Administrative Committee on Coordination/Sub-Committee on Nutrition and International Food Policy Research Institute - Seventh 
Report of the World Nutrition Situation. Geneva, Switzerland. 2010.

[11] Sareen A, Mahajan K, Singh S. Maternal anemia and its effect on cord hemoglobin. Indian Medical Gazette 2013: p. 161-3.

[12] Adediran A, Gbadegesin A, Adeyemo TA, et al. Cord blood haemoglobin and ferritin concentrations in newborns of anaemic and non-anaemic mothers in
Lagos, Nigeria. Nigerian Medical Journal 2013;54(1):22-6. doi:10.4103/0300-1652.108889.

[13] Terefe B, Birhanu A, Nigussie P, et al. Effect of maternal iron deficiency anemia on the iron store of newborns in Ethiopia. Article ID 808204, Anemia 2015;(2015): p. 6.

http://dx.doi.org/10.1155/2015/808204. 